\title{
Modelling the impact of interventions on the progress of the COVID-19 outbreak including age segregation
}

\author{
Jorge Rodríguez ${ }^{1 *}$, Mauricio Patón ${ }^{1}$, Joao M Uratani ${ }^{1}$ and Juan M Acuña² \\ ${ }^{1}$ Department of Chemical Engineering. College of Engineering. Khalifa University. \\ SAN Campus PO Box 2533 Abu Dhabi, United Arab Emirates \\ ${ }^{2}$ Department of Epidemiology and Public Health. College of Medicine. Khalifa University. \\ PO Box 127788 Abu Dhabi, United Arab Emirates
}

"Corresponding author: jorge.rodriguez@ku.ac.ae

\begin{abstract}
Infectious diseases can be devastating, especially when new and highly contagious, producing epidemic outbreaks that can become pandemics. Such is the case of COVID-19, the worst pandemic the world has seen in more than 100 years. Predicting the course and outcomes of such a pandemic in relation to possible interventions is crucial for societal and healthcare planning and forecasting of resource needs. In this work a deterministic model was developed, using elements from the SIR-type models, that describes individuals in a population in compartments by infection stage and age group. The model assumes a close well-mixed community with no migrations. Infection rates and clinical and epidemiological information govern the transitions between stages of the disease. The present model provides a platform to build upon and its current low complexity retains accessibility to both experts and non-experts as well as policy makers to comprehend the variables and phenomena at play.

The impact of several possible interventions that have been or may be applied to slow the spread of the COVID-19 outbreak is evaluated. Key findings in our model simulation results indicate that (i) universal social isolation measures may be effective in reducing total fatalities only if they are strict and the average number of daily social interactions is reduced to very low numbers; (ii) selective isolation of only the age groups most vulnerable to the disease (i.e. older than 60) appears almost as effective in reducing total fatalities but at a much lower economic damage; (iii) the use of protective equipment (PPE) appears capable of very significantly reducing total fatalities if implemented extensively and to a high degree; (iv) extensive random testing of the population leading to infection recognition and subsequent immediate (self) isolation of the infected individuals, appears to be an ineffective intervention due to the required (unreachable with existing test sensitivities) high percentage of infection detections and the incapability to be sustained over time; $(v)$ an increase in the number of critical care beds to directly save significant numbers of lives with a direct reduction in total final fatalities per each extra available critical care bed unit.
\end{abstract}


medRxiv preprint doi: https://doi.org/10.1101/2020.04.04.20053017; this version posted June 25, 2020. The copyright holder for this preprint (which was not certified by peer review) is the author/funder, who has granted medRxiv a license to display the preprint in

It is made available under a CC-BY-NC-ND 4.0 International license .

\section{Introduction}

Mathematical modelling of the spread of diseases has a long history. Epidemiology models can be either deterministic or stochastic. Deterministic compartmental models (DCM) known as SIR (Susceptible-Infected-Recovered) models were published in the early $20^{\text {th }}$ century (Kermack \& McKendrick, 1927). The acronym of the model is based on which compartments of people are included within the model. Developments of the SIR models have resulted in different variations such as SEIR/MSEIR/SEIQJR and other compartmental models (Hethcote, 2000). Deterministic epidemic models allow for the understanding of the population-based dynamics as well as for the identification of parameters of interest (e.g. transmission rates). Numerous examples of deterministic SIR (or variations of SIR) models have been published in the literature (May \& Anderson, 1979; Ruan \& Wang, 2003; Li et al., 2004).

Alternative modelling approaches have focused on the randomness nature of the spread of a disease, particularly at the start of an outbreak, when a low number of people are infected. Therefore, stochastic modelling can be an adequate approach to model such spread events (Britton, 2010). Most of the stochastic models for spread diseases have evolved into network models (McCallum et al., 2001; Keeling \& Eames, 2005; Small and Tse, 2005; Ferguson et. al. 2006; Grassly \& Fraser, 2008; Keeling \& Rohani, 2008; Balcan et al., 2010; Gray et al., 2011; Brauer et al., 2012; Miller et al., 2012; Siettos \& Russo, 2013; Pastor-Satorras et al., 2015). In any case, the outputs of the epidemic models are frequently used to inform studies on health projections and play an important role in shaping policies related to public health (Murray and Lopez, 1997a, 1997b, 1997c, and 1997d; Ferguson et al., 2006).

Data timelines and availability has greatly increased in recent years, which led to direct improvements in epidemic models (Colizza et al., 2006; Riley, 2007; Siettos \& Russo, 2013). These models can help in providing a more comprehensive understanding of recent outbreaks of diseases such as Ebola (Gomes et al., 2014; WHO Ebola Response Team, 2014) and Zika (Zhang et al., 2017). However, all modelling efforts are highly dependent on several elements: a deep understanding of the course of the disease; a comprehensive algorithm of clinical and public health options available and stages of events; probability of such options given certain conditions of the system; identification of parameters that reflect such events and their probabilities (such as mortality by age, infectiousness by contacts, etc.); best assumptions for parameters with insufficient data; and valid data for those parameters that allow the calibration and posterior validation of the forecasts (Tizzoni et al., 2012). In order to obtain a proper and timely identification of parameters for the models, access to up-to-date data is required, in this case of the COVID-19 spread (Dong et al., 2020).

In viral pandemics in particular, one of those parameters, the direct estimation of infected subpopulation fractions, is not feasible using available epidemiological data (unless universal, highly sensitive testing is used, which is rarely possible to implement in these situations), particularly if very mild cases, asymptomatic infections or pre-symptomatic transmission are observed or expected. This was the case of the previous Influenza A (H1N1-2009) pandemic (Nishiura et al., 2011) and it is the observation for the COVID-19 pandemic (Russell et al., 2020). Thus, in many cases, modelling uses a combination of the best available data from historical events and datasets, parameter estimation and assumptions. Then, data about these parameters are computed with statistical tools for the identification of parameters that are used in epidemic models (Cooper et al., 2006; Biggerstaff et al., 2014).

The most challenging cases for the understanding of the potential spread of a disease is when a novel disease outbreak emerges in global populations (Anderson \& May, 1992). The characteristics of the novel disease (e.g.: $R_{0}$, fatality rate and the clinical course of the disease) are unknown as the 
medRxiv preprint doi: https://doi.org/10.1101/2020.04.04.20053017; this version posted June 25, 2020. The copyright holder for this preprint (which was not certified by peer review) is the author/funder, who has granted medRxiv a license to display the preprint in It is made available under a CC-BY-NC-ND 4.0 International license .

data availability is limited (e.g. novelty of pathogen; delay of communication of case datasets from public health workers and facilities to researchers) or biased (e.g., limited availability of testing capacity; undefined or partially defined diagnostics for disease). With novel disease-specific epidemic models, the development of models as low complexity as possible but with as many meaningful parameters as needed, is paramount. These parameters can be accurately defined with data as the infection progresses and data become more available, and the model may be posited as a potential tool to inform public health policy and impact mitigation strategies (Berezovskaya et al., 2005; Hall et al., 2007; Bettencourt et al., 2008; Nishiura, 2011; Wang \& Zhao, 2012; Lee et al., 2013; Nsoesie et al., 2014, Chowell et al., 2016, Rivers et al., 2019, Chowell et al., 2020).

The COVID-19 outbreak and posterior pandemic has brought unprecedented attention into these kinds of modelling and its limitations, with multiple epidemic models and disease spread forecasts being published as more data becomes available. These models have evaluated the ongoing course of the disease spread evolution, from the earlier dynamics of transmission from initial cases (Kucharski et al., 2020), to the potential of non-pharmaceutical interventions to limit the disease spread, such as: international travel restrictions (Chinazzi et al., 2020), contact tracing and isolation of infected individuals at onset (Hellewell et al., 2020), different scales of social distancing and isolation (Flaxman et al., 2020, Prem et al., 2020). Other statistical models tried to estimate fundamental characteristics (i.e. potential model parameters) for the disease, such as the incubation period (Lauer et al., 2020) as well as to assess short-term forecasts (Roosa et al., 2020). Given the inherent uncertainty associated with most of the parameters used, stochastic approaches are employed in the above models.

Effective communication between health care and public health systems and science hubs is considered one of the bigger challenges in both health sciences and public health (Zarcadoolas, 2010; Squiers et al., 2012). In health care It is not only necessary to take effective measures but also to do it timely. This requires strategies for data sharing, generation of information and knowledge and timely dissemination of such knowledge for effective implementations. User-accessible modelling tools can contribute to the understanding by broader audiences (researchers, public health authorities, and the general public) of what to expect on the propagation of infectious diseases and how specific interventions may help. This increased awareness of the disease behaviour and potential course in time by public and policy makers can directly and positively impact the outcome of epidemic outbreaks (Funk et al., 2009).

The present work presents a fully deterministic SIR-type model aimed at the evaluation of intervention scenarios for the COVID-19 outbreak. The model introduces the novel approach of compartmentalisation by age groups and known disease stages, crucial and specific level of complexity for COVID-19 prediction. This aims at retaining mechanistic meaning of all variables and parameters while capturing the relevant phenomena at play. The complexity level was limited specifically to maintain accessibility to non-experts and policy makers to comprehend the model results such that expert advice and decision making can be brought closer together to help guide interventions for immediate and longer-term needs.

\section{Model description}

The model presented is based on balances of individuals, segregated by age group, transitioning between infection stages. All individuals are placed in a common single domain or closed community (e.g. a well-mixed city or town), no geographical clustering nor separation of any type is considered, nor is any form of migration in or out of the community. Large cities with ample use of public transportation are thought to be settings best described by the model. 
medRxiv preprint doi: https://doi.org/10.1101/2020.04.04.20053017; this version posted June 25, 2020. The copyright holder for this preprint (which was not certified by peer review) is the author/funder, who has granted medRxiv a license to display the preprint in It is made available under a CC-BY-NC-ND 4.0 International license.

The model also provides a direct estimation of the dynamic reproduction number or reproductive rate $\left(R_{t}\right)$ (Delamater et al. 2019; De Serres et al. 2000; Lihong et al. 2020) under different circumstances of individual characteristics (such as use of personal protection or awareness) as well as under population-based interventions (such as imposed social isolation). $R_{t}$ is a dynamic number often quoted erroneously as a constant for a specific microorganism or disease. The ability to estimate the $R_{t}$ for different times of the outbreak (given the interventions), outbreak settings and interventions is considered to be a valuable characteristic of the model. $R_{t}$ is predicted to change over time with interventions not related to increased immunity (isolation or use of personal protection equipment (PPE), as opposed to vaccination).

\section{Model constituents}

The model solves dynamic variables or states. Every individual belongs, in addition to their age group (which she/he never leaves), to only one of the possible states that correspond to stages of the infection in terms of infectiousness and severity of symptoms, namely: healthy susceptible $(\mathrm{H})$; presymptomatic non-infectious (NI); pre-symptomatic infectious (PS); symptomatic (S); in need of hospitalisation (SH); in need of critical care (SC); deceased (D) and recovered immune (R).

Definitions of the model state variables are shown in Table 1. Each variable is a state vector with the number of individuals in that stage per age group, which is defined per decade from 0-9 to 80+ year olds ( 9 age groups). Therefore, each state is a vector of dimensions $1 \times 9$, and the total number of states is a matrix of dimensions $8 \times 9$. Note that vector variables and parameters are represented in bold font and scalar ones in regular font.

Table 1. Model states in vectors (1x9) of number of individuals in each infection stage.

\begin{tabular}{lcc}
\hline Definition “Number of individuals...” & Variable & Totals of all ages \\
\hline Healthy susceptible to infection & $\mathbf{N}_{\mathrm{h}}$ & $\mathrm{N}_{\mathrm{hT}}$ \\
Non-infectious pre-symptomatic & $\mathbf{N}_{\mathrm{ni}}$ & $\mathrm{N}_{\mathrm{nT}}$ \\
Infectious pre-symptomatic & $\mathbf{N}_{\mathrm{ps}}$ & $\mathrm{N}_{\mathrm{psT}}$ \\
Infectious symptomatic & $\mathbf{N}_{\mathrm{s}}$ & $\mathrm{N}_{\mathrm{sT}}$ \\
Requiring hospitalisation & $\mathbf{N}_{\mathrm{sh}}$ & $\mathrm{N}_{\mathrm{shT}}$ \\
Requiring critical care & $\mathbf{N}_{\mathrm{sc}}$ & $\mathrm{N}_{\mathrm{scT}}$ \\
Deceased & $\mathbf{N}_{\mathrm{d}}$ & $\mathrm{N}_{\mathrm{dT}}$ \\
Recovered \& immune & $\mathbf{N}_{\mathrm{r}}$ & $\mathrm{N}_{\mathrm{rT}}$ \\
\hline
\end{tabular}

Figure 1 shows the population progress through stages as described in the model. An additional schematic representation of the model approach with the population groups considered for the infection stages, rates of infection and transition between groups and showing possible interactions between population groups is shown in Figure S5. 
medRxiv preprint doi: https://doi.org/10.1101/2020.04.04.20053017; this version posted June 25,2020 . The copyright holder for this preprint (which was not certified by peer review) is the author/funder, who has granted medRxiv a license to display the preprint in It is made available under a CC-BY-NC-ND 4.0 International license.

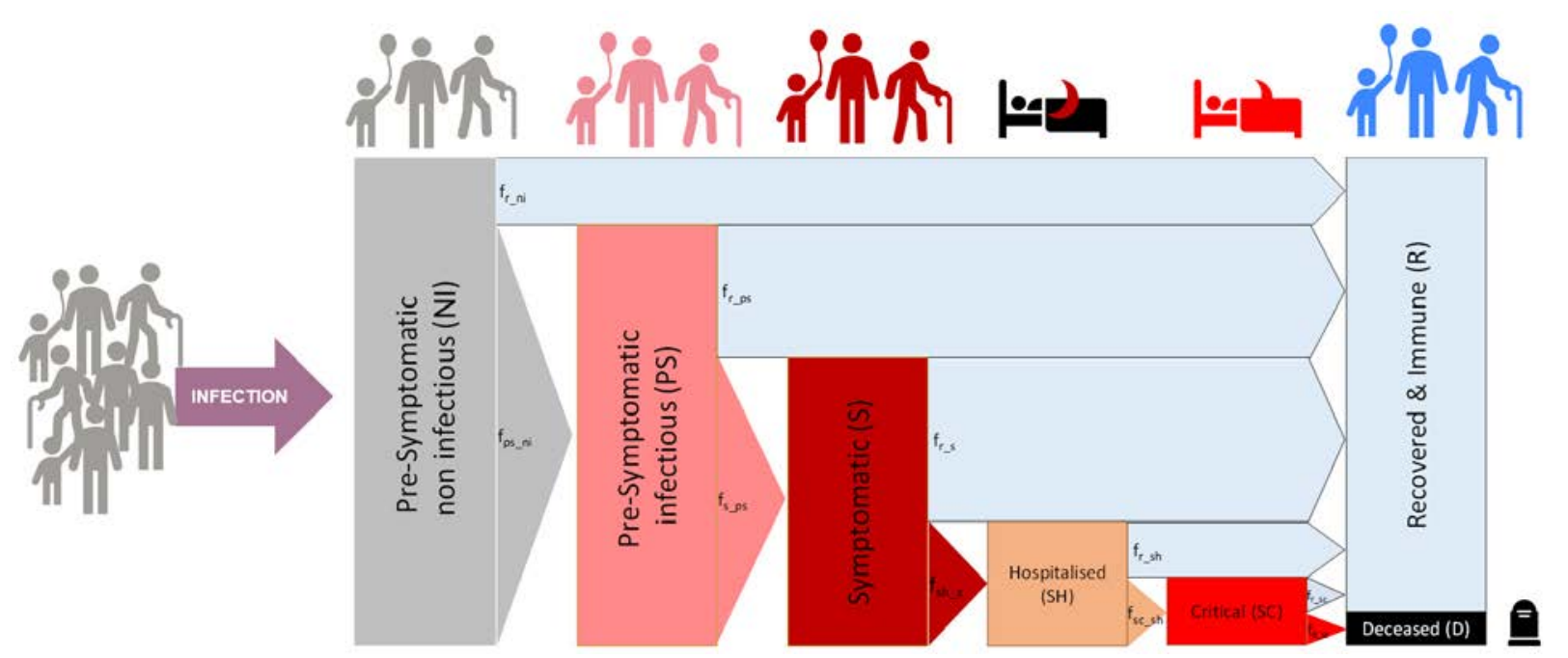

Figure 1. Schematic representation of the population compartments by infection stages and age. Only interactions between infectious individuals (both pre-symptomatic and symptomatic) and healthy susceptible ones can increase the rate of infections.

\section{Rates of transition between infection stages}

The transitions between stages are governed by the rates of infection and transition shown in Table 2 .

Table 2. Rates of infection and transition between states, vectors (1x9).

\begin{tabular}{|c|c|c|}
\hline Definition "Rate of ..." & Variable & Units \\
\hline Infection by interaction with infectious pre-symptomatic & $\mathbf{r}_{\text {i_ps }}$ & \# H infected/day \\
\hline Infection by interaction with infectious symptomatic & $\mathbf{r}_{\mathrm{i}_{-} \mathrm{s}}$ & \# H infected/day \\
\hline Transition from non-infectious to infectious pre-symptomatic & $r_{p s \_n i}$ & \# NI to PS / day \\
\hline Transition from pre-symptomatic to symptomatic & $\mathbf{r}_{\mathrm{s} \_\mathrm{ps}}$ & \# PS to S / day \\
\hline Transition from symptomatic to hospitalised & $r_{\text {sh_s }}$ & \# S to SH / day \\
\hline Transition from hospitalised to critical & $\mathbf{r}_{\mathrm{sc} \_ \text {sh }}$ & \# SH to SC / day \\
\hline Transition from critical to deceased & $r_{d_{-} s c}$ & \# SC to D / day \\
\hline Recovery from pre-symptomatic non-infectious & $\mathbf{r}_{r_{n} \text { ni }}$ & \# NI to R / day \\
\hline Recovery from pre-symptomatic infectious & $\mathbf{r}_{r_{-} p s}$ & \# PS to R / day \\
\hline Recovery from symptomatic & $\mathbf{r}_{r_{-} s}$ & \# S to R / day \\
\hline Recovery from hospitalised & $\mathbf{r}_{r_{-} \text {sh }}$ & \# SH to R / day \\
\hline Recovery from critical & $r_{r_{-} s c}$ & \# SC to R / day \\
\hline
\end{tabular}

The average rates of transition between states are defined such that the latest epidemiological and clinical data can be used to determine and continuously update the parameters as more knowledge of the disease emerges. These parameters include the proportion of individuals that transition to a more severe stage or recover (see Table 3 ) and the average times reported at each stage before transition or recovery (see Table 4).

Table 3. Epidemiological parameters (all in vectors per age group).

\begin{tabular}{lcl}
\hline Definition & Parameter & Units \\
\hline Fraction of NI that will become PS & $f_{\text {ps_ni }}$ & $\# P S / \# N I$ \\
\hline
\end{tabular}


medRxiv preprint doi: https://doi.org/10.1101/2020.04.04.20053017; this version posted June 25, 2020. The copyright holder for this preprint (which was not certified by peer review) is the author/funder, who has granted medRxiv a license to display the preprint in It is made available under a CC-BY-NC-ND 4.0 International license.

\begin{tabular}{|c|c|c|c|}
\hline Fraction of PS that will become $S$ & & $f_{s_{-} p s}$ & \#S/\#PS \\
\hline Fraction of S that will become SH & & $f_{\text {sh_s }}$ & \#SH/\#S \\
\hline Fraction of SH that will become SC & & $f_{\text {sc_sh }}$ & \#SC/\#SH \\
\hline Fraction of cared SC that will die into $D$ & & $f_{\text {d_sc }}$ & $\# \mathrm{D} / \# \mathrm{SC}_{\mathrm{IC}}$ \\
\hline Fraction of $\mathrm{NI}$ that will recover into $\mathrm{R}^{1}$ & $\left(1-f_{p s \_n i}\right)$ & $f_{r_{-} n i}$ & \#R/\#NI \\
\hline Fraction of PS that will recover into $\mathrm{R}^{1}$ & $\left(1-f_{s_{-} p s}\right)$ & $f_{r_{-} \text {ps }}$ & \#R/\#PS \\
\hline Fraction of $S$ that will recover into $\mathrm{R}^{1}$ & $\left(1-f_{\text {sh_s }}\right)$ & $f_{r_{-} s}$ & $\# \mathrm{R} / \# \mathrm{~S}$ \\
\hline Fraction of $\mathrm{SH}$ that will recover into $\mathrm{R}^{1}$ & $\left(1-f_{s c_{-} s h}\right)$ & $f_{r_{-} \text {sh }}$ & \#R/\#SH \\
\hline Fraction of cared SC that will recover into $\mathrm{R}^{1}$ & $\left(1-f_{d_{-} s c}\right)$ & $f_{r_{-} s c}$ & $\# \mathrm{R} / \# \mathrm{SC}_{\mathrm{IC}}$ \\
\hline
\end{tabular}

${ }^{1}$ Calculated by difference with the complementary, not an input parameter

Table 4. Clinical average times in each infection stage (all in vectors per age group).

\begin{tabular}{|c|c|c|}
\hline Definition & Parameter & Units \\
\hline Time to become infectious & $t_{p s \_n i}$ & days \\
\hline Time to develop symptoms from infectious & $\mathbf{t}_{s_{-} \text {ps }}$ & days \\
\hline Time to require hospitalisation from symptoms onset & $\mathbf{t}_{\text {sh_s }}$ & days \\
\hline Time to require critical care from hospitalisation & $\mathbf{t}_{\mathrm{sc} \_ \text {sh }}$ & days \\
\hline Time to death from critical & $\mathbf{t}_{\mathbf{d}_{-} s c}$ & days \\
\hline Time to death from critical with no care available & $t_{d_{d} n c}$ & days \\
\hline Time to recover from presymptomatic non-infectious & $t_{r_{-} n i}$ & days \\
\hline Time to recover from presymptomatic infectious & $t_{r_{-} p s}$ & days \\
\hline Time to recover from (non-severe) symptoms & $\mathbf{t}_{\mathrm{r}_{-} \mathrm{s}}$ & days \\
\hline Time to recover from hospitalisation & $t_{r_{-} s h}$ & days \\
\hline Time to recover from critical & $t_{r_{-} s c}$ & days \\
\hline
\end{tabular}

The rates of transition between stages (in number of individuals per day) are described in Eqs. 1.a-f. All rates are vectors per age group of dimensions (1x9). Note that point operators between vectors indicate an operation element-by-element.

$$
\begin{aligned}
& r_{n i \_h}=r_{i_{\_} p s} .+r_{i_{-} s} \\
& r_{p s \_n i}=\left(f_{p s \_n i} / t_{\text {ps_ni }}\right) * N_{n i} \\
& r_{s_{-} p s}=\left(f_{s_{-} p s} . / t_{s \_p s}\right) \cdot{ }^{*} N_{p s} \\
& r_{\text {sh_s }}=\left(f_{s h_{-} s} \cdot / t_{s h_{-} s}\right) \cdot{ }^{*} \mathbf{N}_{s} \\
& r_{\text {sc_sh }}=\left(f_{\text {sc_sh }} \cdot / t_{s c_{-} s h}\right) \cdot{ }^{*} N_{s h}
\end{aligned}
$$

The rates of individuals recovering from the different infected stages (in number of individuals per day) are described in Eqs 2.a-e. (all rates in vectors per age group).

$$
\begin{aligned}
& r_{r_{-} n i}=\left(f_{r_{-} \text {ni }} / t_{r_{-} n i}\right) \cdot N_{n i} \\
& r_{r_{-} p s}=\left(f_{r_{-} p s .} / t_{r_{-} p s}\right) \cdot N_{p s} \\
& r_{r_{-} s}=\left(f_{r_{-} s} \cdot / t_{r_{-} s}\right) \cdot N_{s} \\
& r_{r_{-} s h}=\left(f_{r_{-} s h} / t_{r_{-} s h}\right) \cdot N_{s h} \\
& r_{r_{-} s c}=\left(f_{r_{-} s c \cdot} / t_{r_{-} s c}\right) \cdot N_{s c \_ \text {ic }}
\end{aligned}
$$


medRxiv preprint doi: https://doi.org/10.1101/2020.04.04.20053017; this version posted June 25, 2020. The copyright holder for this preprint (which was not certified by peer review) is the author/funder, who has granted medRxiv a license to display the preprint in It is made available under a CC-BY-NC-ND 4.0 International license .

The rate of transition from critical to deceased is the sum of that of those critical receiving intensive care ( $\left.\mathbf{r}_{d_{\text {_scic }}}\right)$ plus that of those critical without available care ( $\left.\mathbf{r}_{\mathbf{d}_{\text {s }} \text { scnc }}\right)$ as per Eqs. 3.a-c. All critical individuals not receiving intensive care $\left(\mathbf{N}_{\text {sc_ncc }}\right)$ are assumed to become fatalities after a time ( $\left.\mathbf{t}_{\mathbf{d} \_n c}\right)$. The allocation of critical care is described below.

where

$$
r_{d_{-} s c}=r_{d_{-} s c i c}+r_{d_{-} s c n c}
$$

$$
\begin{aligned}
& \mathbf{r}_{d_{-} s c i c}=\left(\mathbf{f}_{d_{\text {d }} s c} / \mathbf{t}_{d_{-} s c}\right) \cdot{ }^{*} \mathbf{N}_{\text {sc_ic }}
\end{aligned}
$$

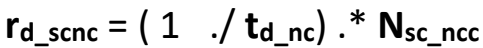

Figure 2 provides a representation of the transition between stages, the proportions of individuals recovering or worsening are as per Figure 1.

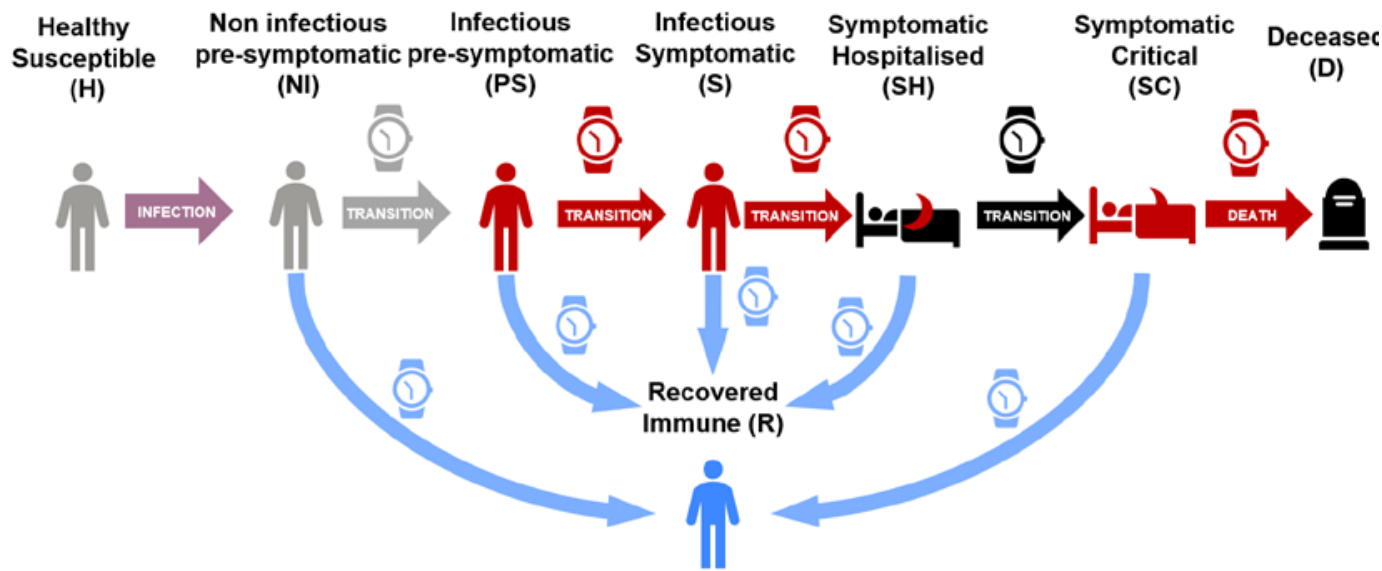

Figure 2. Schematic representation of the transitions rates between stages. Individuals spend in each stage an amount of time depending on their transition path towards recovery or increased severity.

\section{Rates of infection}

The infection of healthy susceptible individuals $(\mathrm{H})$ is modelled as occurring only via their interaction with infectious either pre-symptomatic (PS) or symptomatic (S) individuals. Hospitalised (SH) and critical (SC) individuals are assumed not available for interactions neither are those deceased (D).

Two rates of infection of healthy susceptible individuals (in number of infections per day) are defined, one from each one of the two possible infecting groups (PS and S). The rates of infection (in vectors per age group) result from the product of (i) the fraction of interactions occurring with PS (or S) individuals among the total interactions $\left(f_{\text {ips }}\right.$ or $f_{\text {is }}$ ) times (ii) the likelihood of contagion in an interaction with PS (or $\mathbf{S}$ ) ( $\mathbf{p}_{\mathbf{i} \_p s}$ or $\mathbf{p}_{\mathbf{i}_{\_} s}$ ) (per age group), (iii) the average number of daily interpersonal contacts that $\mathrm{H}$ individuals have $\left(\mathbf{n i}_{\mathbf{h}}\right)$ and (iv) the number of $\mathrm{H}$ individuals themselves (per age group) (see Eqs 4.a-b and Figure 3).

$$
\begin{aligned}
& \mathbf{r}_{\text {i_ps }}=\mathbf{N}_{\mathbf{h}} \cdot{ }^{*} \mathbf{n i}_{\mathrm{h}} * f_{\mathrm{ips}} \cdot{ }^{*} \mathbf{p}_{\mathrm{i} \_p s ;}
\end{aligned}
$$

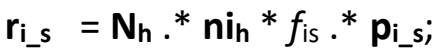


medRxiv preprint doi: https://doi.org/10.1101/2020.04.04.20053017; this version posted June 25, 2020. The copyright holder for this preprint (which was not certified by peer review) is the author/funder, who has granted medRxiv a license to display the preprint in It is made available under a CC-BY-NC-ND 4.0 International license .

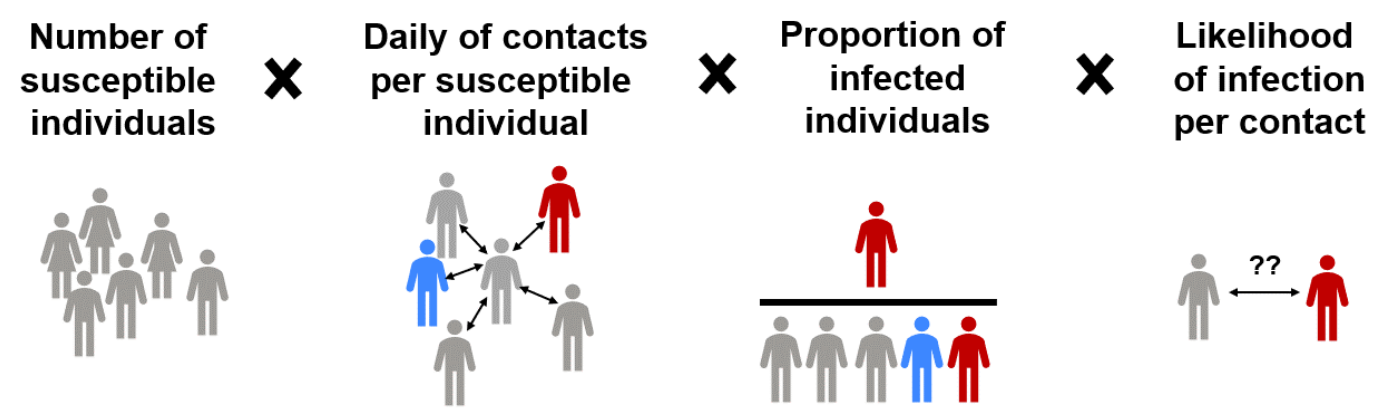

Figure 3. Schematic representation of the terms of the infection rate.

\section{Modelling interventions}

Four main possible interventions are evaluated that have been or may be applied to slow the spread of the COVID-19 outbreak namely (i) the degree of social isolation of the individuals in the population, in terms of the average number of interpersonal contacts that individuals have per day with other interacting individuals; (ii) the level of personal protection and awareness that individuals apply to protect themselves and others against contagion during interactions; (iii) the percentage of infected-aware individuals due to testing that will subsequently quarantine and (iv) the intensive care capacity available. These interventions can be stratified by age groups. Table 5 describes the key parameters that define the interventions.

\section{Social isolation}

The degree of social isolation is described through its impact on the parameter $\left(\mathbf{n} \mathbf{i}_{h}\right.$ ) (vector per age group) corresponding to the representative average number of interpersonal contacts that healthy susceptible individuals have with others per day. Different $\mathbf{n i}_{\mathbf{h}}$ values can be applied to different age groups to describe age selective isolation strategies such as e.g. isolation of the elderly and/or the young alone.

\section{Use of PPE and safety distance}

The level of PPE use and awareness is described as impacting the likelihood of infection (see Eqs. 4) through the parameters (Ipah) for healthy and (Ipa $a_{p s}$ and $\left.I p a_{s}\right)$ for infectious PS and S individuals (both in vectors per age group). Values of the Ipa parameters can vary between 0 and 1, with 1 corresponding to the use of complete protective measures and zero to the most reckless opposite situation. Different values can be assigned e.g. for children and adults as well as for those suffering from symptoms (S).

The likelihoods of infection per interaction are calculated as per Eq. 5.a-b.

$$
\begin{aligned}
& p_{i \_p s}=\left(1-\mid p a_{h}\right) \cdot *\left(1-\mid p a_{p s}{ }^{a v}\right) ; \\
& \mathbf{p}_{\mathrm{i}_{\mathrm{s}} \mathrm{s}}=\left(1-\mid \mathbf{p a} \mathrm{a}_{\mathrm{h}}\right) \cdot{ }^{*}\left(1-\mid \mathrm{pa}_{\mathrm{s}}{ }^{\mathrm{av}}\right) ;
\end{aligned}
$$

where Ipan reflects a level of protection and awareness related to interventions and defined below; $\mathrm{Ipa}_{\mathrm{as}}{ }^{\mathrm{av}}$ and $\mathrm{Ipa}_{\mathrm{s}}{ }^{\mathrm{av}}$ are scalars corresponding to the weighted averages over all age groups of the pool of PS and $\mathrm{S}$ with which $\mathrm{H}$ individuals can interact (Eqs 5.c-d).

$$
\begin{aligned}
& \mid p a_{p s}{ }^{a v}=\Sigma\left(N_{a s} \cdot{ }^{*} \mid p a_{p s}\right) / N_{\text {ast }} \\
& \mid p a_{s}{ }^{a v}=\Sigma\left(N_{s} \cdot{ }^{*} \mid p a_{s}\right) / N_{s T}
\end{aligned}
$$

where $\mathrm{N}_{\mathrm{ps}}$ and $\mathrm{N}_{\mathrm{sT}}$ are the total numbers of PS and $\mathrm{S}$ individuals of all ages respectively. The $\Sigma$ symbol indicates summation across all age groups. 
medRxiv preprint doi: https://doi.org/10.1101/2020.04.04.20053017; this version posted June 25, 2020. The copyright holder for this preprint (which was not certified by peer review) is the author/funder, who has granted medRxiv a license to display the preprint in It is made available under a CC-BY-NC-ND 4.0 International license .

\section{Awareness of infection by testing}

The awareness of infection after positive testing is described through a reduction factor of interactions (quarantine) of infected-aware individuals. Symptomatic individuals are already assumed to have a self or imposed partial precautionary element of quarantine even if unaware of infection, this is described by the parameter $\left(\mathbf{r f i}_{\mathbf{s}}\right)$. Also, in asymptomatic and mild disease individuals tested, the sensitivity of the tests is around $80 \%$. In other words, of every 100 infected individuals tested, only 80 will yield a positive test and 20 will be false negative tests .

The awareness of infection after a positive test is assumed to lead to a full quarantine and removes those individuals from regular interaction with others. The fractions of individuals (without and with symptoms) aware of infection is therefore equal to the product of the fraction of total individuals randomly tested from the entire population ( $\mathrm{pt}_{\mathrm{ps}}$ for PS) and from the entire pool of individuals showing symptoms ( $\mathrm{t}_{s}$ for $\mathrm{S}$ ) times the corresponding test sensitivity $\left(\mathrm{t}_{\text {sns_ps }}\right.$ and $\mathrm{t}_{\text {sns_s }}$ respectively). Different types of tests may be available or adequate for each of the two groups.

The fractions of infectious PS and $S$ individuals that remain in interaction with others $\left(f_{\text {ips }}\right.$ and $f_{\text {is }}$ ) are therefore calculated as per Eqs 5.e-f. Hospitalised, critical and deceased are considered excluded from the pool of interacting individuals.

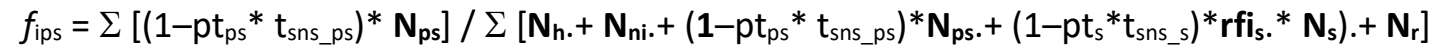

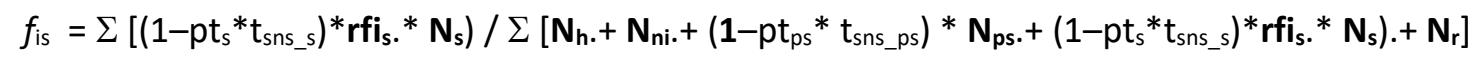

where $\mathrm{pt}_{\mathrm{s}}$ is the proportion of symptomatic individuals tested (randomly) and $\mathrm{pt}_{\mathrm{ps}}$ is the proportion of randomly tested non-symptomatic individuals of all types. For symptomatic $\mathrm{S}$ individuals both RTqPCR and serological tests are assumed possible while, for non-symptomatic, only RT-qPCR tests. The parameters $t_{\text {sns_s }}$ and $t_{\text {sns_ps }}$ refer to the sensitivity of the tests for both groups respectively. Table 5 shows the definitions and units of all the parameters used in the modelling of interventions.

Table 5. Intervention parameters

\begin{tabular}{|c|c|c|}
\hline Definition & Parameter & Units \\
\hline Average daily individual contacts by $\mathrm{H}$ & $\mathbf{n i}_{\mathrm{h}}$ & \#interactions / $\mathrm{H}$ individual.day \\
\hline Personal protection and awareness by $\mathrm{H}^{1}$ & $\mid p a_{h}$ & $\varnothing$ \\
\hline Personal protection and awareness by PS ${ }^{1}$ & Ipaps & $\varnothing$ \\
\hline Personal protection and awareness by $\mathrm{S}^{1}$ & $\mathrm{Ipa}_{\mathrm{s}}$ & $\varnothing$ \\
\hline Likelihood of infection by interaction with $\mathrm{PS}^{2}$ & $\mathbf{p}_{\text {i_ps }}$ & infections / interactions with PS \\
\hline Likelihood of infection by interaction with $\mathrm{S}^{2}$ & $\mathbf{p}_{\mathrm{i} \_s}$ & infections / interactions with S \\
\hline Percentage of tested individuals from $\mathrm{PS}^{1}$ & $\mathrm{pt}_{\mathrm{ps}}$ & \#random (non S) tested/\#(H+NI+PS) \\
\hline Percentage of tested individuals from $\mathrm{S}^{1}$ & $\mathrm{pt}_{\mathrm{s}}$ & $\#$ random S tested/\#S \\
\hline Test sensitivity on PS & $t_{\text {sns_ps }}$ & \#PS detected / \#PS tested \\
\hline Test sensitivity on $\mathrm{S}$ & $t_{\text {sns_s }}$ & \#S detected / \#S tested \\
\hline Reduction of interactions by unaware $S^{1}$ & $\mathrm{rfi}_{\mathrm{s}}$ & $\varnothing$ \\
\hline
\end{tabular}

${ }^{1}$ Values only within the interval $[0,1] ;{ }^{2}$ Calculated, not an input parameter.

\section{Critical care capacity}

The impact of available critical care capacity is modelled by a specific function to allocate critically ill individuals as per the available ICU. The function allocates critically ill individuals in two possible groups, namely those admitted to ICU ( $\mathbf{N}_{\text {sc_ic }}$ ) and those not admitted to ICU due to lack of capacity 
medRxiv preprint doi: https://doi.org/10.1101/2020.04.04.20053017; this version posted June 25, 2020. The copyright holder for this preprint (which was not certified by peer review) is the author/funder, who has granted medRxiv a license to display the preprint in It is made available under a CC-BY-NC-ND 4.0 International license.

or for medical or humanitarian reasons ( $\left.\mathbf{N}_{\text {sc_ncc }}\right)$. At each simulation time point the allocation function is computed for the total $\mathbf{N}_{\mathbf{s c}}$ per age group.

The function allocates ICU resources with priority to age groups with higher ICU survival rate $\left(f_{r_{-} s c}\right)$ until the maximum number of intensive care units is reached leaving any remaining individuals without care, in this way $\mathbf{N}_{\text {sc_ic }}$ and $\mathbf{N}_{\text {sc_ncc }}$ are computed.

As the COVID-19 outbreak has progressed, data indicate that not all patients in critical condition have been admitted into intensive care units (ICU). Data show that many individuals with very poor prognosis, particularly those of oldest age may have never been referred to ICU due to capacity limitations or other medical humanitarian reasons. This is based on data from Spain (Ministerio Sanidad España: Act. 107 COVID-19) showing that for individuals over 70, only a fraction of the reported fatalities previously hospitalised was ever admitted to ICU and this was not due to ICU lack of capacity. In order to maintain consistency with the reported data (Ministerio Sanidad España: Act. 107 COVID-19) the parameters of $f_{d_{-} s c}$ and $f_{\text {sc_sh }}$ have been estimated such that the product of $\mathrm{f}_{\mathrm{d}_{\mathrm{sc}}} * \mathrm{f}_{\mathrm{sc} \_ \text {sh }}$ (fatality ratios over hospitalised individuals) is consistent with reported numbers for all ages irrespective of reported ICU admissions.

\section{Stage transition equations}

The dynamic variation on the number of individuals in each stage over time and per age group is governed by the population balance equations described in Eqs 5.a-h. (all in vectors by age group).

$$
\begin{aligned}
& \mathrm{d} \mathbf{N}_{\mathrm{h}} / \mathrm{dt}=-\mathbf{r}_{\text {ni_h }} \\
& \mathrm{d} \mathbf{N}_{\text {ni }} / \mathrm{dt}=r_{\text {ni_h }} .-r_{\text {ps_ni }} \cdot-r_{r_{-} n i} \\
& \mathrm{~d} \mathbf{N}_{\mathrm{ps}} / \mathrm{dt}=\mathbf{r}_{\mathrm{ps} \_\mathrm{h}} .-\mathbf{r}_{\mathrm{s}_{-} p s} .-\mathbf{r}_{r_{-} p s} \\
& \mathrm{~d} \mathbf{N}_{s} / \mathrm{dt}=\mathrm{r}_{\mathrm{s}_{-} p s} .-\mathrm{r}_{\text {sh_s }} .-\mathbf{r}_{\mathrm{r}_{-} \mathrm{s}} \\
& d N_{s h} / d t=r_{s h \_s} .-r_{s c \_s h} .-r_{r_{-} s h} \\
& \mathrm{dN}_{\mathrm{sc}} / \mathrm{dt}=\mathrm{r}_{\mathrm{sc} \_} \mathrm{sh} .-\mathrm{r}_{\mathrm{d}_{-} s \mathrm{sc}} \cdot-\mathrm{r}_{\mathrm{r}_{-} s \mathrm{sc}} \\
& \mathrm{d} \mathbf{N}_{\mathrm{d}} / \mathrm{dt}=\mathbf{r}_{\mathrm{d}_{-} s c} \\
& d N_{r} / d t=r_{r_{-} p s}+r_{r_{-} s} .+r_{r_{-} s h} .+r_{r_{-} s c}
\end{aligned}
$$

The state transitions as governed by these rates are represented in a matrix form in Figure S2.

\section{Calculation of the dynamic reproduction number $\left(R_{t}\right)$}

The reproduction number refers to the potential infection of susceptible individuals from infected individuals (Delamater et al. 2019). Since the model produces, for each parameters set used, a unique deterministic set of values for its outputs over at any given time, an instantaneous deterministic estimation of the reproduction number $\left(R_{t}\right)$ is also obtained. Several parameters and variables influence the $R_{t}$ including the duration of infectious stages; the likelihoods of infection per social contact as well as the percentages of individuals transitioning to more severe stages.

The dynamic reproduction number $\left(R_{t}\right)$ during the outbreak is computed over time according to Eq. 6 from the current values of the model state variables. Under this approach, infectious individuals can only infect others while they are in pre-symptomatic (PS) and symptomatic (S) stages. Although it has been speculated that post-symptomatic recovered individuals may be infectious for some period of time, this has not been considered in the model at this time due to lack of data. Hospitalised and critical individuals are assumed to be well isolated and also not able 
medRxiv preprint doi: https://doi.org/10.1101/2020.04.04.20053017; this version posted June 25, 2020. The copyright holder for this preprint (which was not certified by peer review) is the author/funder, who has granted medRxiv a license to display the preprint in It is made available under a CC-BY-NC-ND 4.0 International license .

to infect others. The provided dynamic output of the reproduction number $R_{t}$ can be used to guide and interpret the impact of interventions in terms of $R_{t}$.

Modelled infected individuals can take only three possible infectious paths, namely: (i) PS $\rightarrow$ R; (ii) PS $\rightarrow S \rightarrow R$ and (iii) PS $\rightarrow S \rightarrow$ SH. These paths are made of combinations of four possible infectious stage intervals in which infected individuals spend time and infect at their corresponding rate (see Table 6).

Table 6. Possible infectious stages intervals for $R_{t}$ computation.

\begin{tabular}{|c|c|c|c|}
\hline $\begin{array}{l}\text { Infectious } \\
\text { interval }\end{array}$ & $\begin{array}{l}\text { Fraction of infected } \\
\text { passing the interval } \\
\left.\text { (ind } \text { interv }_{\text {ind }} \text { inf }\right)\end{array}$ & $\begin{array}{l}\text { Interval } \\
\text { duration } \\
\text { (d) }\end{array}$ & $\begin{array}{c}\text { Total infections per stage interval per } \\
\text { individual infected } \\
\left.\text { (inf }_{\text {interv }} / \text { ind }_{\text {inf }}\right)\end{array}$ \\
\hline $\mathrm{PS} \rightarrow \mathrm{R}$ & $f_{r_{-} p s}$ & $t_{r_{-} p s}$ & $\left(r_{i \_p s t} / N_{p s T}\right) * t_{r_{-} p s} \cdot{ }^{*} f_{r_{-} p s}$ \\
\hline $\mathrm{PS} \rightarrow \mathrm{S}$ & $\left(1-f_{r_{-} p s}\right)$ & $t_{\text {s_ps }}$ & $\left(r_{r_{\_} p s t} / N_{p s T}\right) * t_{s_{-} p s} *\left(1-f_{r_{-} p s}\right)$ \\
\hline$S \rightarrow R$ & $\left(1-\mathbf{f}_{r_{-} p s}\right) * \mathbf{f}_{r_{-} s}$ & $t_{r_{-} s}$ & $\left(r_{i_{\_} s T} / N_{s T}\right) * t_{r_{-} s} \cdot *\left(1-f_{r_{-} p s}\right) \cdot * f_{r_{-} s}$ \\
\hline $\mathrm{S} \rightarrow \mathrm{SH}$ & $\left(1-f_{r_{-} p s}\right) *\left(1-f_{r_{-} s}\right)$ & $t_{\text {sh_s }}$ & $\left(r_{i_{\_} s t} / N_{s T}\right) * t_{s h_{-} s} \cdot *\left(1-f_{r_{-} p s}\right) \cdot *\left(1-f_{r_{-} s}\right)$ \\
\hline
\end{tabular}

The dynamic computation of $R_{t}$ consists of adding the total infection contributions of every stage interval as shown in Eq. 7.

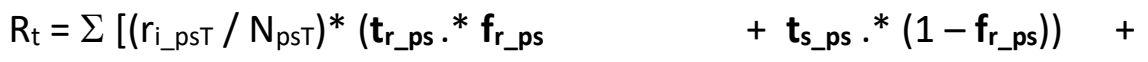

$$
\begin{aligned}
& \left.\left(r_{i_{\_} s t} / N_{s T}\right) *\left(t_{r_{-} s} \cdot *\left(1-f_{r_{-} p s}\right) * f_{r_{-} s}+t_{s_{-} s} \cdot *\left(1-f_{r_{-} p s}\right) . *\left(1-f_{r_{-} s}\right)\right)\right]
\end{aligned}
$$

in which, the age group weighted average rates of infection by PS and $\mathrm{S}$ are given as per Eqs. 6a-b.

$$
\begin{aligned}
& \left.r_{i \_p s T}=\sum\left(r_{i \_p s} .{ }^{*} N_{p s}\right) / N_{p s T}\right) \quad\left[\text { inf }_{p S} / \text { ind }_{p s} \cdot d\right]
\end{aligned}
$$

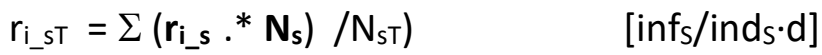

\section{Model limitations}

The model shares many of the fundamental characteristics of compartment SIR-type models and is based on dynamic balances of individuals in compartments classified by their stage of infection and age groups only, no other differentiation within those groups is captured by the model. This characteristic allows for the model application only to single, densely populated clusters. The model has a low complexity and requires a small number of parameters that are also mechanistic and meaningful. Most of these parameters can be directly estimated from epidemiological and clinical data and are not recommended for calibration against data. Analogous to all SIR-type models this model carries limitations since all variables and parameters refer to representative averages for each compartment of stage and age group. This may limit the model representation of the non-linear interactions that occur in reality. Phenomena like so-called super spread events or any location specific phenomena are not reproduced by these types of models. Any quantitative interpretation of results for prediction purposes should therefore be always accompanied by a critical discussion against these limitations.

\section{Impact of interventions on a COVID-19 outbreak case study}

A case study based on a scenario of propagation of the COVID-19 pandemic using data available as of May 2020 is presented below. The results obtained are intended to be interpreted qualitatively and to be contextualized to the specific setting characteristics. They serve also as a demonstration of the model potential if applied with higher confidence parameter values. Several selected scenarios were simulated aimed at illustrating the impact of different interventions. 
medRxiv preprint doi: https://doi.org/10.1101/2020.04.04.20053017; this version posted June 25, 2020. The copyright holder for this preprint (which was not certified by peer review) is the author/funder, who has granted medRxiv a license to display the preprint in It is made available under a CC-BY-NC-ND 4.0 International license .

Default reference epidemiological and clinical parameter values were extracted from different information sources on the COVID-19 outbreak as available in May 2020. Details of values and sources are provided in the Supplementary Information Tables S1-S2 respectively, with indications of the level of confidence. A population with an age distribution as that of the region of Madrid (Spain) in 2019 was used (INE Spain, 2020) during the simulations.

Default reference values for interventions-related parameters were selected arbitrarily for a situation assimilated to that previous to the outbreak and without any specific intervention (see values and rationale in the Supplementary Information Table S3). The value for available intensive care beds per million people (caplCpM) of 261 has been used by default in all case studies. The dynamic simulation results of the default outbreak scenario under no intervention is shown in the Supplementary Information Figure S4.

All scenarios are simulated for 365 days and evaluated in terms of (i) final total number of fatalities at outbreak termination and (ii) final number of fatalities per age group. In addition, the scenarios are presented also in terms of dynamic profiles over time for (iii) number of active cases; (iv) reproduction number; (iv) number of critical cases; (v) number of fatalities.

\section{Intervention \#1. Social isolation}

In this scenario, the impact of the level of imposed social isolation was evaluated by age brackets. Four cases are shown, namely universal social isolation, that for elderly only, youngsters only, and elderly and youngsters only.

The parameter that describes this intervention is the reduction in the number of interpersonal contacts that healthy susceptible individuals have with others per day $\left(\mathbf{n i}_{\mathbf{h}}\right)$. Figure 4 shows the comparison between the impacts of the four types of isolations. The Supplementary Information Appendix $\mathrm{VI}$ contains the complete results of the four isolation intervention types.

It appears that the intervention starts to be effective in terms of significantly reducing total deaths after the number of daily contacts is placed below a threshold number, above which there is minor impact. Interestingly, the $\mathrm{ni}_{\mathrm{h}}$ does not appear to significantly modify total final mortality beyond one single contact per day. The number of fatalities appears clearly and directly related to social isolation as well as the speed at which the fatalities saturation will occur. Full details can be seen in Figures S6. The model is capable of capturing this partly due to its description of the saturation of the healthcare capacity and withdrawal of critical care over capacity.

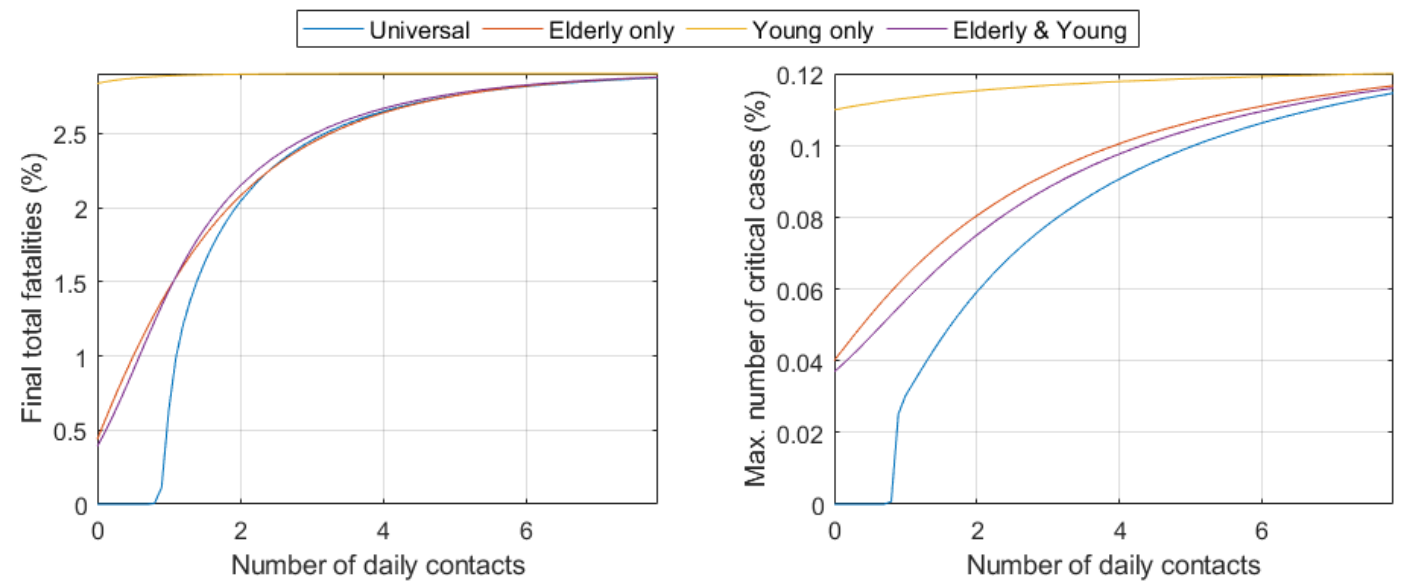

Figure 4. Impact of the level of social isolation under the four different strategies universal and per age groups on the total number of fatalities at the end of the outbreak (left) and on the maximum critically ill individuals ever reached during the outbreak (right). Numbers are as percentage of the total population. 
medRxiv preprint doi: https://doi.org/10.1101/2020.04.04.20053017; this version posted June 25, 2020. The copyright holder for this preprint (which was not certified by peer review) is the author/funder, who has granted medRxiv a license to display the preprint in It is made available under a CC-BY-NC-ND 4.0 International license .

The middle and bottom graphs in Figure $\mathbf{S 6}$. a show the impact of nih on the time course of several variables. Figure S6.a (middle left) supports the "flatten the curve" concept, now globally popular. If interactions are not modified, the number of cases grows rapidly explosively. Figure S6.a(middle right) shows the estimate of $R_{t}$ over time. This illustrates how the level of social isolation can define the infectability and the number of cases each infected individual will infect $\left(R_{t}\right)$ showing how factors such as interventions can impact $R_{t}$. The number of critical cases increases throughout time as the social interaction increases Figure S6.a(bottom left).

The detailed results of imposed social isolation selective to those over 60 years old is shown in Figure S6.b. As shown in Figure 4 the selective social isolation of the elderly has a potentially very significant impact on final total fatalities at an almost comparable level than for universal isolation. This is a result with potentially significant consequences as it indicates that a sustained isolation selective only to the elderly and not to the other age groups could alleviate the economic damage at a cost of a small number of increased total fatalities. The decrease in social interactions in schools and colleges by isolation of the young may however have an impact on the overall multiplier of infections from youngsters to adults.

The impact of selective imposed social isolation of only those under 20 years old was also evaluated. Figure S6.C shows the results for this scenario, for the output variables indicated, in absence of other interventions. The young population have been observed to be quite resistant to the disease. The isolation of the young produces no effect in the overall final fatality rate but produces a moderate impact on the mortality of the elderly at low values of $\mathrm{ni}_{\mathrm{h}}$. As it can be seen in Figure 4, social isolation of the young has little impact producing almost identical curves for any levels of social isolation. It is thought however that the decrease in social interactions in schools and colleges by isolation of the young may have a large impact on the overall multiplier of infections from youngsters to adults. This emergent aspect of the disease spread behaviour and containment efforts is captured in our results, even though the present model does not incorporate geographical features and does not explicitly describe location-specific population interactions (such as those synthetic location-specific contact patterns in Prem et al., 2020).

The fourth case of selective imposed social isolation for both those under 20 and those over 60 years old is also evaluated. The number of daily social contacts with other people that healthy susceptible individuals of the age groups under 20 and over 60 years old have $\left(\mathbf{n i}_{\mathbf{h}}\right)$ is modified. The full results for this scenario are shown in Figure S6.d.

Many of the early interventions during the COVID-19 outbreak started by protecting the elderly and isolating the young (no schools, no colleges or universities for students), decreasing the number of interactions of the two subpopulations substantially. The isolation of these population groups together results in similar effects to that of the isolation of the elderly alone with no significant added value in isolating the young respect to that the elderly alone as shown in Figure 4.

\section{Intervention \#2. Use of PPE and safety distance}

The impact of increased use of PPE and social distancing awareness is evaluated in this scenario. The parameter that describes this intervention is a factor increasing the default values (see Table S3) of the level of personal protection and awareness (Ipa) parameters of the healthy and infected population groups ( $\left(\mathrm{lap}_{\mathrm{h}}, \mathrm{lap}_{\mathrm{ps}}\right.$ and $\left.\mid \mathrm{Ipa}_{\mathrm{s}}\right)$. Increases in these parameters decrease the likelihood of infection per interaction (see Eqs. 4) and subsequently the rates of infection (Eqs. 5) . Figure 5 presents the main impacts of on this intervention on the total final fatalities and peaks of critical cases. More complete results, including the predictions of the dynamic reproduction number $\mathrm{R}_{\mathrm{t}}$, are presented in Figure S7. 
medRxiv preprint doi: https://doi.org/10.1101/2020.04.04.20053017; this version posted June 25,2020 . The copyright holder for this preprint (which was not certified by peer review) is the author/funder, who has granted medRxiv a license to display the preprint in It is made available under a CC-BY-NC-ND 4.0 International license .
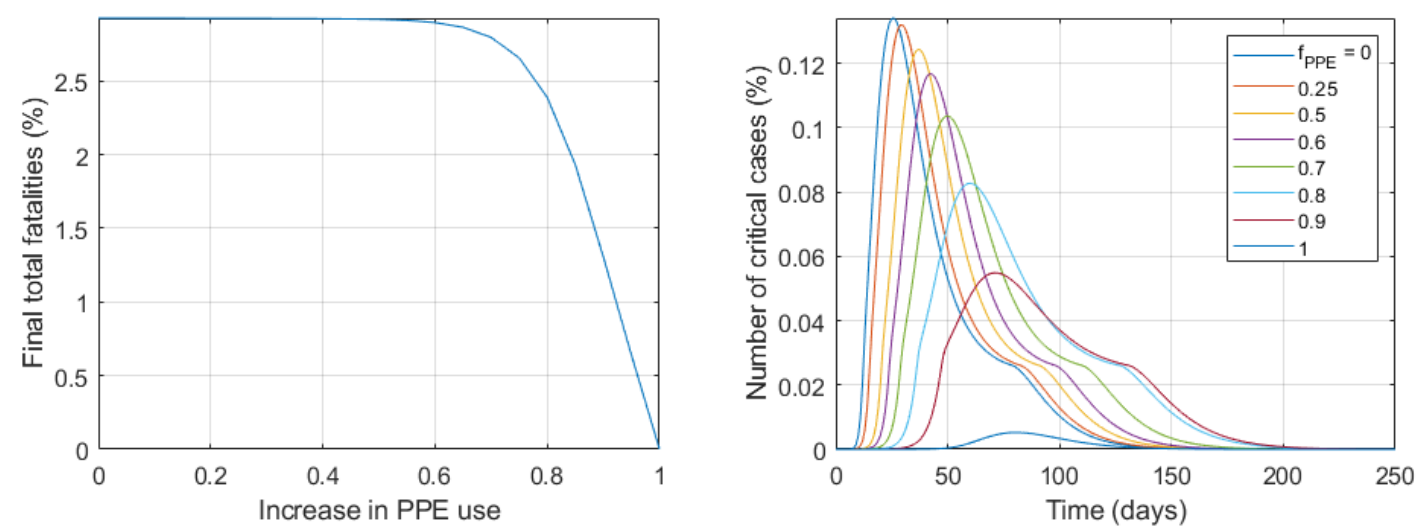

Figure 5. Impact of the level of PPE use and social distancing on the total number of fatalities at the end of the outbreak (left) and on the peaks of critically ill individuals (right). Numbers are as percentage of the total population.

As it is shown in Figure 5 the extensive use of PPE appears as having a potentially major impact on total outbreak fatalities at the highest levels of protection. There is an inverse relationship between the level of protection and the overall fatality of the disease. The peak of number of cases is reached earlier and is higher if low levels of personal protection are used, the infectability and $\mathrm{R}_{\mathrm{t}}$ follow the same pattern. The height of the peak number of critical cases is much lower is extensive use of PPE is implemented as seen in Figure 5 (right), if the peak does not exceed the critical care capacity the total number of fatalities reaches much smaller values.

\section{Intervention \#3. Awareness of infection by testing}

The impact of widespread extensive testing is evaluated in this scenario. The effect of the percentage of detected infections on the final total fatalities and outbreak dynamics is evaluated. The compared impact of testing only symptomatic individuals, testing randomly only the nonsymptomatic population (therefore the same fraction of pre-symptomatic) and testing everyone both with and without symptoms. The fractions of infections detected in each group (S and PS) is the product of the fraction of the group tested $\mathrm{pt}_{\mathrm{s}}$ or $\mathrm{pt}_{\mathrm{ps}}$ respectively times the sensitivity of each group's test $t_{\text {sns_s }}$ and $t_{\text {sns_ps }}$ (different test sensitivities for each type of test apply).

The model describes the impact of infection detection as a reduction in the fraction of infectious (PS and S) individuals available for interactions among the total ones. This due to their knowledge of infection and subsequent (self)quarantine. See Eq. 5.e-f. These reduced fractions of infectious individuals among total reduces the rates of infection by both groups (Eq. 4.a-b).

If only symptomatic individuals are tested, the impact is almost negligible and only when both $\mathrm{S}$ and PS groups are extensively tested to levels allowing for a detection of near $90 \%$ of total infections a meaningful impact is predicted. The current test sensitivities (around $80 \%$ ) imply that even at $100 \%$ of population tested those high levels of detentions required will be unachievable and a large number of infections will remain undetected yielding the intervention ineffective.

The results clearly show that extensive testing appears as a non-effective intervention due to the unreachable very high percentage of infection detections required for it to have an impact (see Figure 6). Figures S8.a-c. show the complete simulation results of the impact of this intervention. 
medRxiv preprint doi: https://doi.org/10.1101/2020.04.04.20053017; this version posted June 25, 2020. The copyright holder for this preprint (which was not certified by peer review) is the author/funder, who has granted medRxiv a license to display the preprint in It is made available under a CC-BY-NC-ND 4.0 International license .

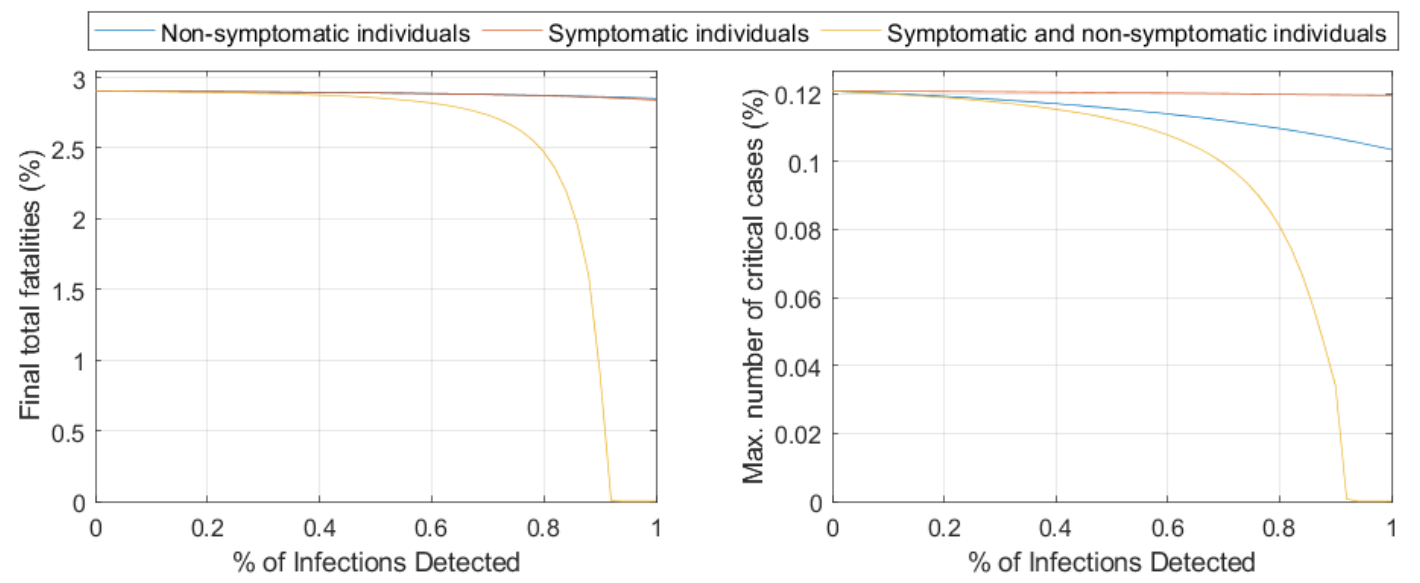

Figure 6. Impact of the infection detection level (product of the proportion of tested individuals times the test the sensitivity, $80 \%$ ) for symptomatic alone, pre-symptomatic alone and for both. The impact on the total number of fatalities at the end of the outbreak (left) and on the maximum values of critically ill individuals ever reached during the outbreak (right) are shown. Numbers are as percentage of the total population.

\section{Intervention \#4. Critical care capacity}

The impact of the availability of intensive care beds is evaluated in this scenario. The parameter that describes this intervention is the number of available intensive care beds per million population. Figure 7 illustrates the model predictions for this scenario, in terms of total final fatalities and numbers of critical cases over time. Note that once the ICU beds capacity is exceeded the critically ill patients become fatalities in one day.
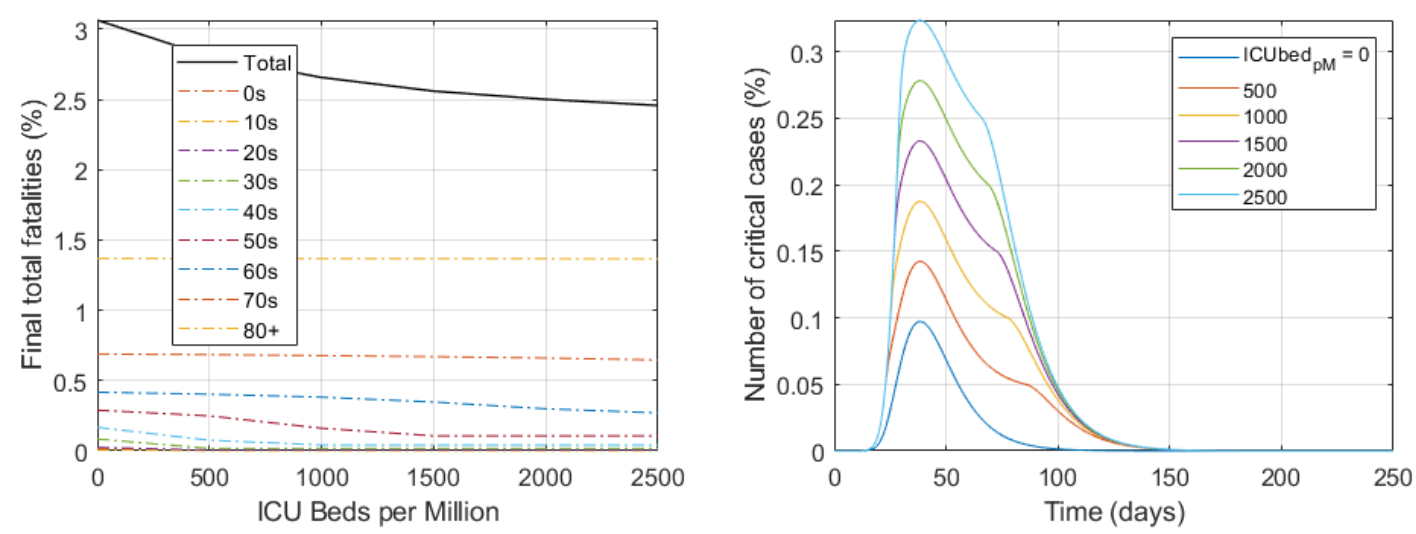

Figure 7. Impact of the availability of intensive care beds on the final number of fatalities total and also per age group (left) as well as for the different time course profiles of the number of critical cases (right). Numbers are in percentage of the total population of all ages.

From Figure 7 (and Figure S9 for more complete details), the enormous impact that the increase in critical care resources can have in decreasing total fatalities becomes evident. The higher the availability of critical beds, the lower number of fatalities, the trend applies until there is no shortage of IC beds and all remaining fatalities are only the unavoidable ones. This intervention avoids those deaths that are preventable by the availability of critical care support for those that need it.

\section{Conclusions on the impact of interventions}

The impact of specific interventions on the outbreak time course, number of cases and outcome of fatalities were evaluated. Data available from the COVID-19 outbreak as of May 2020 was used. Our results on the impact and mechanism of several interventions indicate that: 
medRxiv preprint doi: https://doi.org/10.1101/2020.04.04.20053017; this version posted June 25, 2020. The copyright holder for this preprint (which was not certified by peer review) is the author/funder, who has granted medRxiv a license to display the preprint in It is made available under a CC-BY-NC-ND 4.0 International license .

1. Universal social isolation measures may be effective in reducing total fatalities only if they are strict and the average number of daily social interactions is reduced to very low numbers. Selective isolation of only the age groups most vulnerable to the disease (i.e. older than 60) appears almost as effective in reducing total fatalities but at a much lower economic damage.

2. The use of protective equipment (PPE) appears capable of very significantly reducing total fatalities if implemented extensively and to a high degree.

3. Extensive random testing of the population leading to infection recognition and subsequent immediate (self) isolation of the infected individuals, appears to be an ineffective intervention due to the required (unreachable with existing test sensitivities) high percentage of infection detections and the incapability to be sustained over time.

4. An increase in the number of critical care beds to directly save significant numbers of lives with a direct reduction in total final fatalities per each extra available critical care bed unit.

It is important to note that any quantitative interpretation of the results must be accompanied with a critical discussion in terms of the model limitations and its frame of application. The sensitivity analysis provided should be used to help such analysis.

\section{Conclusions on model application and roadmap for model expansion}

The confidence in the model is based on the confidence of its epidemiological and clinical parameters. As time passes the quality of data towards this end is increasing rapidly. Any calibration of epidemiological or clinical parameters against dynamic data curves is not recommended as it will likely lead to model overfitting. Instead, valid epidemiological and clinical sources should be used for estimation, and not calibration, of these parameters.

Only the intervention parameters are recommended for calibration using dynamic data curves and should be conducted against data from representative populated cities or well mixed communities. Data from cities in which population is typically interconnected socially in public areas and public transport is widely used and are particularly well suited to the calibration of these parameters. The use of dynamic data for entire countries with regions in which the outbreak may be in different stages is not recommended. The recommendation then is to fit the model to each independent, similar population. This type of model does not represent well the outbreak dynamics unless the population is well mixed and in the same outbreak stage.

More detailed descriptions and sub models of some of the intervention relevant parameters such as the levels of social interaction and personal protection measures are avenues for model further development.

The model modularity and its fast computation allows for its easy scale up into multiple population nucleus that could be simulated in parallel with degrees of interconnectivity among them. Separate independent copies of the model can be run in parallel one for e.g. each city in a region or country and migration terms can be added between cities. Interventions can then be defined to include e.g. travel restrictions between those cities at different levels.

The mechanistic nature of the model makes it also very suitable for the evaluation of advanced optimisation and optimum control strategies. Its capacity of describing complex interactions makes it also of potential use to develop advanced artificial intelligence (AI) algorithms to aide and provide advice to authorities during decision making. Al algorithms could be trained by evaluation of very large numbers of scenarios combining static and dynamic interventions of different types against total fatalities and economic damage. 
medRxiv preprint doi: https://doi.org/10.1101/2020.04.04.20053017; this version posted June 25, 2020. The copyright holder for this preprint (which was not certified by peer review) is the author/funder, who has granted medRxiv a license to display the preprint in It is made available under a CC-BY-NC-ND 4.0 International license .

\section{Additional Information and source code}

The for Matlab ${ }^{\circledR}$ source code and Excel file containing all parameter values used as well as a nonage segregated version of the model are available at $h$ ttps://github.com/EnvBioProM/COVID_Model

\section{Acknowledgements}

All authors wish to thank Khalifa University (Grant 8474000317 CRPA-2020-SEHA) and the Government of Abu Dhabi for the funding and support.

\section{References}

Anderson, R. M., Anderson, B., \& May, R. M. (1992). Infectious diseases of humans: dynamics and control. Oxford university press.

Balcan, D., Gonçalves, B., Hu, H., Ramasco, J. J., Colizza, V., \& Vespignani, A. (2010). Modeling the spatial spread of infectious diseases: The GLobal Epidemic and Mobility computational model. Journal of computational science, 1(3), 132-145.

Bendix A. (2020) A day-by-day breakdown of coronavirus symptoms shows how the disease, COVID-19, goes from bad to worse. Business Insider (last accesed 30-3-2020) https://www.businessinsider.com/coronavirus-covid19-day-by-day-symptoms-patients-2020-2

Berezovskaya, F., Karev, G., Song, B., \& Castillo-Chavez, C. (2005). A simple epidemic model with surprising dynamics. Mathematical Biosciences \& Engineering, 2(1), 133.

Bettencourt, L. M., \& Ribeiro, R. M. (2008). Real time bayesian estimation of the epidemic potential of emerging infectious diseases. PLoS One, 3(5).

Biggerstaff, M., Cauchemez, S., Reed, C., Gambhir, M., \& Finelli, L. (2014). Estimates of the reproduction number for seasonal, pandemic, and zoonotic influenza: a systematic review of the literature. BMC infectious diseases, 14(1), 480.

Brauer, F., Castillo-Chavez, C., \& Castillo-Chavez, C. (2012). Mathematical models in population biology and epidemiology (Vol. 2). New York: Springer.

Britton, T. (2010). Stochastic epidemic models: a survey. Mathematical biosciences, 225(1), 24-35.

Capasso, V., \& Wilson, R. E. (1997). Analysis of a reaction-diffusion system modelling man-environmentman epidemics. SIAM Journal on Applied Mathematics, 57(2), 327-346.

Chinazzi, M., Davis, J.T., Ajelli, M., Gioannini, C., Litvinova, M., Merler, S., y Piontti, A.P., Mu, K., Rossi, L., Sun, K. and Viboud, C. (2020). The effect of travel restrictions on the spread of the 2019 novel coronavirus (COVID-19) outbreak. Science. 06 Mar 2020:eaba9757

Chowell, G., Luo, R., Sun, K., Roosa, K., Tariq, A., \& Viboud, C. (2020). Real-time forecasting of epidemic trajectories using computational dynamic ensembles. Epidemics, 30, 100379.

Chowell, G., Sattenspiel, L., Bansal, S., \& Viboud, C. (2016). Mathematical models to characterize early epidemic growth: A review. Physics of life reviews, 18, 66-97.

Colizza, V., Barrat, A., Barthélemy, M., \& Vespignani, A. (2006). The role of the airline transportation network in the prediction and predictability of global epidemics. Proceedings of the National Academy of Sciences, 103(7), 2015-2020.

Cooper, B. S., Pitman, R. J., Edmunds, W. J., \& Gay, N. J. (2006). Delaying the international spread of pandemic influenza. PLoS medicine, 3(6).

Delamater, P. L., Street, E. J., Leslie, T. F., Yang, Y., \& Jacobsen, K. H. (2019). Complexity of the Basic Reproduction Number $\left(\mathrm{R}_{0}\right)$. Emerging Infectious Diseases, 25(1), 1-4. https://dx.doi.org/10.3201/eid2501.171901.

De Serres G, Gay NJ, Farrington CP. Epidemiology of transmissible diseases after elimination. Am J Epidemiol. 2000;151(11):1039-1052. doi:10.1093/oxfordjournals.aje.a010145

Dong, E., Du, H., \& Gardner, L. (2020). An interactive web-based dashboard to track COVID-19 in real time. The Lancet Infectious Diseases. 
medRxiv preprint doi: https://doi.org/10.1101/2020.04.04.20053017; this version posted June 25, 2020. The copyright holder for this preprint (which was not certified by peer review) is the author/funder, who has granted medRxiv a license to display the preprint in It is made available under a CC-BY-NC-ND 4.0 International license.

Fenichel, E.P., Castillo-Chavez, C., Ceddia, M.G., Chowell, G., Parra, P.A.G., Hickling, G.J., Holloway, G., Horan, R., Morin, B., Perrings, C. and Springborn, M. (2011). Adaptive human behavior in epidemiological models. Proceedings of the National Academy of Sciences, 108(15), 6306-6311.

Ferguson NM et al. (2020) Impact of non-pharmaceutical interventions (NPIs) to reduce COVID19 mortality and healthcare demand. $h$ ttps://spiral.imperial.ac.uk/handle/10044/1/77482

Ferguson, N. M., Cummings, D. A., Fraser, C., Cajka, J. C., Cooley, P. C., \& Burke, D. S. (2006). Strategies for mitigating an influenza pandemic. Nature, 442(7101), 448-452.

Flaxman S, Mishra S, Gandy A et al. (2020) Estimating the number of infections and the impact of nonpharmaceutical interventions on COVID-19 in 11 European countries. Imperial College London

Flaxman, S. et al. (2020) Report 13: Estimating the number of infections and the impact of nonpharmaceutical interventions on COVID-19 in 11 European countries. Imperial College London

Funk, S., Gilad, E., Watkins, C., \& Jansen, V. A. (2009). The spread of awareness and its impact on epidemic outbreaks. Proceedings of the National Academy of Sciences, 106(16), 6872-6877.

Gomes, M. F., y Piontti, A. P., Rossi, L., Chao, D., Longini, I., Halloran, M. E., \& Vespignani, A. (2014). Assessing the international spreading risk associated with the 2014 West African Ebola outbreak. PLoS currents, 6.

González-Peñas H, Lu-Chau T, LemaJM and Rodríguez J (2020) A microbial population dynamics model for the Acetone-Butanol-Ethanol fermentation process. Authorea. February 22, 2020. DOI: https://doi.org/10.22541/au.158240035.50698760

Grassly, N. C., \& Fraser, C. (2008). Mathematical models of infectious disease transmission. Nature Reviews Microbiology, 6(6), 477-487.

Gray, A., Greenhalgh, D., Hu, L., Mao, X., \& Pan, J. (2011). A stochastic differential equation SIS epidemic model. SIAM Journal on Applied Mathematics, 71(3), 876-902.

Hall, I. M., Gani, R., Hughes, H. E., \& Leach, S. (2007). Real-time epidemic forecasting for pandemic influenza. Epidemiology \& Infection, 135(3), 372-385.

Hellewell, J., Abbott, S., Gimma, A., Bosse, N.I., Jarvis, C.I., Russell, T.W., Munday, J.D., Kucharski, A.J., Edmunds, W.J., Sun, F. and Flasche, S. (2020). Feasibility of controlling COVID-19 outbreaks by isolation of cases and contacts. The Lancet Global Health.

Henze, M., Gujer, W., Mino, T., \& van Loosdrecht, M. C. (2000). Activated sludge models ASM1, ASM2, ASM2d and ASM3. IWA publishing.

Hethcote, H. W. (2000). The mathematics of infectious diseases. SIAM review, 42(4), 599-653.

Hu, Z., Song, C., Xu, C., Jin, G., Chen, Y., Xu, X., Ma, H., Chen, W., Lin, Y., Zheng, Y., et al. (2020). Clinical characteristics of 24 asymptomatic infections with COVID-19 screened among close contacts in Nanjing, China. Sci China Life Sci 63, https://doi.org/10.1007/s11427-020-1661-4

INE Spain (2020) https://www.ine.es/ (last accessed31/3/2020)

Keeling, M. J., \& Eames, K. T. (2005). Networks and epidemic models. Journal of the Royal Society Interface, 2(4), 295-307.

Keeling, M. J., \& Rohani, P. (2008). Modeling infectious diseases in humans and animals. Princeton University Press.

Kermack, W. O., \& McKendrick, A. G. (1927). A contribution to the mathematical theory of epidemics. Proceedings of the Royal Society of London. Series A, Containing papers of a mathematical and physical character, 115(772), 700-721.

Kucharski, A.J., Russell, T.W., Diamond, C., Liu, Y., Edmunds, J., Funk, S., Eggo, R.M., Sun, F., Jit, M., Munday, J.D. and Davies, N. (2020). Early dynamics of transmission and control of COVID-19: a mathematical modelling study. The lancet infectious diseases.

Lauer, S.A., Grantz, K.H., Bi, Q., Jones, F.K., Zheng, Q., Meredith, H.R., Azman, A.S., Reich, N.G. and Lessler, J. (2020). The incubation period of coronavirus disease 2019 (COVID-19) from publicly reported confirmed cases: estimation and application. Annals of internal medicine.

Lee, B. Y., Haidari, L. A., \& Lee, M. S. (2013). Modelling during an emergency: the 2009 H1N1 influenza pandemic. Clinical Microbiology and Infection, 19(11), 1014-1022. 
medRxiv preprint doi: https://doi.org/10.1101/2020.04.04.20053017; this version posted June 25,2020 . The copyright holder for this preprint (which was not certified by peer review) is the author/funder, who has granted medRxiv a license to display the preprint in It is made available under a CC-BY-NC-ND 4.0 International license .

Li, J., Zhou, Y., Ma, Z., \& Hyman, J. M. (2004). Epidemiological models for mutating pathogens. SIAM Journal on Applied Mathematics, 65(1), 1-23.

Lihong H., Sipeng S. , Ping Y., Yongyue W. (2020) Evaluation of the status of prevention and control of new coronavirus pneumonia based on dynamic basic regeneration number. Chinese Journal of Epidemiology, 41: Online pre-publishing . DOI: 10.3760/cma.j.cn112338-20200209-00080

Liu, Y., Gayle, A. A., Wilder-Smith, A., \& Rocklöv, J. (2020). The reproduction number of COVID-19 is higher compared to SARS coronavirus. Journal of travel medicine.

May, R. M., \& Anderson, R. M. (1979). Population biology of infectious diseases: Part II. Nature, 280(5722), 455-461.

McCallum, H., Barlow, N., \& Hone, J. (2001). How should pathogen transmission be modelled?. Trends in ecology \& evolution, 16(6), 295-300.

Miller, J. C., Slim, A. C., \& Volz, E. M. (2012). Edge-based compartmental modelling for infectious disease spread. Journal of the Royal Society Interface, 9(70), 890-906.

Ministerio de Sanidad de España. Actualización n67: enfermedad por SARS-CoV-2 (COVID-19) 03.04.2020 https://www.mscbs.gob.es/profesionales/saludPublica/ccayes/alertasActual/nCovChina/documentos/Actualizacion_74_COVID-19.pdf

Murray, C. J., \& Lopez, A. D. (1997a). Mortality by cause for eight regions of the world: Global Burden of Disease Study. The Lancet, 349(9061), 1269-1276.

Murray, C. J., \& Lopez, A. D. (1997b). Regional patterns of disability-free life expectancy and disabilityadjusted life expectancy: Global Burden of Disease Study. The Lancet, 349(9062), 1347-1352.

Murray, C. J., \& Lopez, A. D. (1997c). Global mortality, disability, and the contribution of risk factors: Global Burden of Disease Study. The Lancet, 349(9063), 1436-1442.

Murray, C. J., \& Lopez, A. D. (1997d). Alternative projections of mortality and disability by cause 19902020: Global Burden of Disease Study. The Lancet, 349(9064), 1498-1504.

Newman ME (2003). The structure and function of complex networks. SIAM review, 45(2), 167-256.

Nishiura H, Kobayashi T, Suzuki A, Jung S-Mok, Hayashi K, Kinoshita R, Yang Y, Yuan B, Akhmetzhanov AR, Linton NM, Miyama T (2020) Estimation of the asymptomatic ratio of novel coronavirus infections (COVID-19), International Journal of Infectious Diseases, doi:https://doi.org/10.1016/j.ijid.2020.03.020

Nishiura, H. (2011). Real-time forecasting of an epidemic using a discrete time stochastic model: a case study of pandemic influenza (H1N1-2009). Biomedical engineering online, 10(1), 15.

Nishiura, H., Chowell, G., \& Castillo-Chavez, C. (2011). Did modeling overestimate the transmission potential of pandemic (H1N1-2009)? Sample size estimation for post-epidemic seroepidemiological studies. Plos one, 6(3).

Nsoesie, E. O., Brownstein, J. S., Ramakrishnan, N., \& Marathe, M. V. (2014). A systematic review of studies on forecasting the dynamics of influenza outbreaks. Influenza and other respiratory viruses, 8(3), 309-316.

Pastor-Satorras, R., Castellano, C., Van Mieghem, P., \& Vespignani, A. (2015). Epidemic processes in complex networks. Reviews of modern physics, 87(3), 925.

Plimpton, S., \& Root, J. (1994). Materials and strategies that work in low literacy health communication. Public Health Reports, 109(1), 86.

Prem, K., Liu, Y., Russell, T.W., Kucharski, A.J., Eggo, R.M., Davies, N., Flasche, S., Clifford, S., Pearson, C.A., Munday, J.D. and Abbott, S. (2020). The effect of control strategies to reduce social mixing on outcomes of the COVID-19 epidemic in Wuhan, China: a modelling study. The Lancet Public Health.

Ramkrishna D and Singh MR (2014) Population Balance Modeling: Current Status and Future Prospects. Annual Review of Chemical and Biomolecular Engineering 5:1, 123-146.

Reluga, T. C. (2010). Game theory of social distancing in response to an epidemic. PLoS computational biology, 6(5).

Riley, S. (2007). Large-scale spatial-transmission models of infectious disease. Science, 316(5829), 12981301. 
medRxiv preprint doi: https://doi.org/10.1101/2020.04.04.20053017; this version posted June 25, 2020. The copyright holder for this preprint (which was not certified by peer review) is the author/funder, who has granted medRxiv a license to display the preprint in It is made available under a CC-BY-NC-ND 4.0 International license .

Rivers, C., Chretien, J.P., Riley, S., Pavlin, J.A., Woodward, A., Brett-Major, D., Berry, I.M., Morton, L., Jarman, R.G., Biggerstaff, M. and Johansson, M.A. (2019). Using "outbreak science" to strengthen the use of models during epidemics. Nature communications, 10(1), 1-3.

Roosa, K., Lee, Y., Luo, R., Kirpich, A., Rothenberg, R., Hyman, J.M., Yan, P. and Chowell, G. (2020). Real-time forecasts of the COVID-19 epidemic in China from February 5th to February 24th, 2020. Infectious Disease Modelling, 5, 256-263.

Ruan, S., \& Wang, W. (2003). Dynamical behavior of an epidemic model with a nonlinear incidence rate. Journal of Differential Equations, 188(1), 135-163.

Russell TW et al. (2020) Using a delay-adjusted case fatality ratio to estimate under-reporting. https://cmmid.github.io/topics/covid19/severity/global_cfr_estimates.html (last access 02/04/2020)

Small, M., \& Tse, C. K. (2005), Small World and Scale Free Model of Transmission of SARS. International Journal of Bifurcation and Chaos 15 (05), 1745.

Siettos, C. I., \& Russo, L. (2013). Mathematical modeling of infectious disease dynamics. Virulence, 4(4), 295-306.

Squiers, L., Peinado, S., Berkman, N., Boudewyns, V., \& McCormack, L. (2012). The health literacy skills framework. Journal of health communication, 17(sup3), 30-54.

Stephen A. Lauer, Kyra H. Grantz, Qifang Bi, Forrest K. Jones, Qulu Zheng, Hannah R. Meredith, Andrew S. Azman, Nicholas G. Reich, Justin Lessler (2020) The Incubation Period of Coronavirus Disease 2019 (COVID-19) From Publicly Reported Confirmed Cases: Estimation and Application. Annals of Internal Medicine, DOI: 10.7326/M20-0504

Tizzoni, M., Bajardi, P., Poletto, C., Ramasco, J.J., Balcan, D., Gonçalves, B., Perra, N., Colizza, V. and Vespignani, A. (2012). Real-time numerical forecast of global epidemic spreading: case study of 2009 A/H1N1pdm. BMC medicine, 10(1), 165.

Wang, W., \& Zhao, X. Q. (2012). Basic reproduction numbers for reaction-diffusion epidemic models. SIAM Journal on Applied Dynamical Systems, 11(4), 1652-1673.

WHO Ebola Response Team. (2014). Ebola virus disease in West Africa - the first 9 months of the epidemic and forward projections. New England Journal of Medicine, 371(16), 1481-1495.

Yang, X. S. (2014). Nature-inspired optimization algorithms. Elsevier.

Zarcadoolas, C. (2011). The simplicity complex: exploring simplified health messages in a complex world. Health promotion international, 26(3), 338-350.

Zhang, Q., Sun, K., Chinazzi, M., y Piontti, A.P., Dean, N.E., Rojas, D.P., Merler, S., Mistry, D., Poletti, P., Rossi, L. and Bray, M. (2017). Spread of Zika virus in the Americas. Proceedings of the National Academy of Sciences, 114(22), E4334-E4343.

Zhou F, Yu T, Du R, et al. (2020) Clinical course and risk factors for mortality of adult inpatients with COVID19 in Wuhan, China: a retrospective cohort study. Lancet published online March 9.

http://dx.doi.org/10.1016/S0140-6736(20)30566-3. 